\title{
The future of medicine
}

\author{
Brighter than you might think
}

Next week the leaders of British doctors will meet to consider the future of medicine. The BMA, the General Medical Council, the royal colleges, and the departments of health will all be represented. This is the first time that these groups have met at such a summit conference since the Christchurch conference of $1961 .^{1}$ That conference led to the present system of postgraduate education. Next week's meeting occurs against a background of falling morale and is a response to a request to doctors from Ken Calman, the chief medical officer of England. ${ }^{2} \mathrm{He}$ asked us to look beyond the current turmoil in the NHS to consider the core values of medicine, and on $\mathrm{p} 1140$ he sets out his vision of the future. One thing we know about the future is that it will be different from now. Doctors tired of change may long for a period of stability, but this will not happen.

We must applaud this gathering of the clans of British medicine because all the evidence suggests that groups that look to the future do much better than those that look mostly to the past, hankering for a golden age that probably never existed. The simple fact that these groups, which often disagree in public and in private, are trying to speak with one voice is also important ( $p$ 1144). It will be important for the clans to consider how the world will change around them, and this editorial looks at changes that are likely to come in medicine, not only in Britain but in all countries. The clans should remember, too, that the common mistake that people make when looking forward is to overestimate the future importance of short term changes and to underestimate the effect of long term change. That is why it will be wise to look beyond the current turmoil in the NHS and not get bogged down in current grievances.

Medicine everywhere is in the midst of profound structural change. No health service is stable, and five key driving forces will continue to transform the practice of medicine well into the next century.

The power of big ugly buyers is the first driving force. Globally, governments, private payers, and individual patients are placing new demands on medical care. The payers in the health care system are demanding cost effectiveness from doctors. Whether they be purchasers in the British NHS or health care coalitions and large employers in the United States, power is shifting - to purchasers. And those purchasers want much better evidence of effectiveness than is currently available for many medical inter- ventions. "Evidence based medicine" is a phrase that is currently familiar to only a few doctors, but all will know it by the millennium.

The rise of sophisticated consumers is the second driving force. No longer patient, these sophisticated consumers and their agents are challenging the unique authority of doctors and insisting on a greater role in clinical decision making. Patients cannot be treated as passive fodder for medical practice. Increasingly patients are as educated as their doctors. Doctors who have treated patients with AIDS have seen this most clearly, but it is spreading across medicine. The doctor-patient relationship, which many see as being at the heart of medicine, will change fundamentally.

New technology is a driving force that has long had an impact on medicine, and the clans will have a session on this force at their meeting. Molecular biology and information technology, both singly and in combination, will transform medicine in the next century. Total exposition of the human genome will raise new insights into disease and may allow effective treatments where none currently exist. The exposition will also allow new methods of diagnosis and deepen our understanding of disease processes: we will be able to predict disease patterns for individual patients. But perhaps more powerful still will be the application of computers and communications to the practice of medicine and the coordination of care. Medicine is an information based activity, yet medical practice has lagged behind industry by decades (some say centuries) in the appropriate use of information technology. ${ }^{3}$ Reuters, which has already wired together the world's financial community, has now taken the strategic decision to wire together doctors and hospitals. The most significant transformations will come from the combination of powerful hand held computers-so called PDAs (personal digital assistants)-wireless communications, and large databases on patients. Together these tools will support the mobile nature of medicine and provide a platform for new approaches to clinical practice in the hospital, the clinic, and the home.

Shifts in the boundaries of health and medicine will be the fourth driving force. Health results from a combination of social, economic, and psychological as well as purely biological phenomena. Most doctors now understand this and so increasingly do politicians; this enhances their 
reluctance to invest heavily in health services when they have only a small effect on health. As science clarifies our understanding of the complex relation between health and the environment of patients, doctors will be drawn into the web of systems around the patients that determine their state of health. New medical disciplines will emerge such as population health informatics, and old disciplines, such as occupational health, will be transformed.

The ethics of controlling human biology will be the final driving force. The mix of new technologies, cost pressures, and sophisticated consumers is a powerful and potentially toxic one. Death and dying will become a major focus of societal debate in the next century as the baby boomers confront their mortality. The legitimacy of rationing-by both public and private payers - on behalf of the patients they serve will come under enormous scrutiny. Debates on the ethics of rationing will not be solved easily by technical analyses; the battles may be ugly, political, and confounded by issues such as race and poverty. Profound questions will be asked about the rights of people to control and shape their own biology and the biology of the unborn. Deep seated beliefs about life, disease, personality, and death will be challenged by the new biology.

It thus makes sense for the British medical clans to concentrate on discussing the core values of medicine. Willard Gaylin, the president of the Hastings Centre, has written: "The most unfortunate thing about the shuttered process [of American health care reform] is that a remarkable opportunity has been missed. What could have been a wide open, far ranging public debate about the deeper issues of health care, our attitudes toward life and death, the goals of medicine, the meaning of "health," suffering versus survival, who shall live and who shall die (and who shall decide) has been supplanted by relatively narrow quibbles over policy." 4 Exactly the same could be written about the debate over health care reforms in Britain and most other countries.

Doctors in most countries currently feel beleaguered. But they shouldn't fear the future. Doctors will be at the centre of the new health system, but not as autocrats. Their dominance as care givers will be eroded by new tools, technology, and systems of care. But doctors have to have a central leadership role in care teams, policymaking, planning, and management. They will increasingly work in teams rather than individually, and they need to understand better how to be effective team players. If doctors do not take up the challenge of leadership in health care but instead retreat to form a selfish artisans' union they will be letting down the patients and the society they swore to serve.

IAN MORRISON

President

Institute for the Future,

2744 Sand Hill Road,

Menlo Park, CA 94025-7020,

USA

RICHARD SMITH

Editor

$B M \mathcal{F}$

London WC1H 9JR

1 Nuffield Provincial Hospitals Trust. Conference on postgraduate medical education. BMY 1962;i:466-7.

2 Smith J. Focus: A rebuke from the chief medical officer. BMF 1994;308:1322.

3 LaPorte RE. How to improve monitoring and forecasting of disease patterns. $B M \mathscr{f}$ 1993;307:1573-4.

4 Gaylin W. Faulty diagnosis: why Clinton's health care plan won't cure what ails us. Harpers Magazine 1993; Oct:57-64.

\section{Divided we fall (yet again)}

\section{The medical profession's need to speak with one voice}

"Hang together or, most assuredly, we shall all hang separately," "Unity is strength", "United we stand-divided we fall,"-all time worn clichés but relevant to doctors today, facing an intransigent government that has little regard for the views of our-or any other-profession. Doctors have wide and varied responsibilities, and inevitably many separate representative bodies and a somewhat diffuse leadership have developed.

The "premier division" contains three or possibly four players: the General Medical Council, the royal colleges (and their conference), and the BMA. To these well defined groups may be added academic medicine and research together with many other smaller but important groupings, such as the Overseas Doctors Association and the Medical Women's Federation. The effectiveness of these bodies varies with the issues under consideration and the abilities of their current leadership. By and large, most seem to perform well when operating within their own specialist fields. But most have less authority and influence when dealing with the more general issues that face the whole profession such as broad medicopolitical matters, the great ethical problems, manpower, and training.

Lately the profession's ability to influence the government seems to have declined (if not disappeared), and our standing in the eyes of the world has been somewhat eroded. The most obvious manifestation of this was the profession's failure to modify the government's plans for reforming the NHS, either during the consultation period or during their passage through parliament. Once the proposals became law the profession accepted the will of parliament, and most doctors have tried to make the reforms work. As, however, it observes the bureaucratic morass that is emerging, together with the fragmentation of the NHS, the drift towards privatisation, and the decline in morale, the profession (as is its duty) continues to offer advice to the government-advice that is largely disregarded. Changing this government's mind by reasoned argument no longer seems an option. Nor does changing governments-but it surely behoves us to re-examine how we present ourselves and our policies, in the hope of finding a more effective machinery than the one that has failed us in recent years.

When dealing in narrow specialist fields it is right for specialist bodies to take the lead and speak with their undoubted authority. But today, few decisions are wholly specialist; most of the important problems that we face cross the borders between several, if not all, of the numerous medical spheres of influence. When faced with serious challenges how much stronger the profession would be if the great medical institutions and their leaders responded only after full consultation with their colleagues and, whenever possible, in a united fashion.

One little known example serves to make the point. When the profession faced an ideological attack on 